\title{
Failure of available scoring systems to predict ongoing infection in patients with abdominal sepsis after their initial emergency laparotomy
}

Oddeke van Ruler ${ }^{1}$, Jordy JS Kiewiet ${ }^{1 *}$, Kimberley R Boer ${ }^{2}$, Bas Lamme ${ }^{1}$, Dirk J Gouma ${ }^{1}$, Marja A Boermeester ${ }^{1}$ and Johannes B Reitsma²

\begin{abstract}
Background: To examine commonly used scoring systems, designed to predict overall outcome in critically ill patients, for their ability to select patients with an abdominal sepsis that have ongoing infection needing relaparotomy.

Methods: Data from a RCT comparing two surgical strategies was used. The study population consisted of 221 patients at risk for ongoing abdominal infection. The following scoring systems were evaluated with logistic regression analysis for their ability to select patients requiring a relaparotomy: APACHE-II score, SAPS-II, Mannheim Peritonitis Index (MPI), MODS, SOFA score, and the acute part of the APACHE-II score (APS).

Results: The proportion of patients requiring a relaparotomy was 32\% (71/221). Only 2 scores had a discriminatory ability in identifying patients with ongoing infection needing relaparotomy above chance: the APS on day 1 (AUC $0.61 ; 95 \% \mathrm{Cl} 0.52-0.69$ ) and the SOFA score on day 2 (AUC $0.60 ; 95 \% \mathrm{Cl} 0.52-0.69$ ). However, to correctly identify $90 \%$ of all patients needing a relaparotomy would require such a low cut-off value that around $80 \%$ of all patients identified by these scoring systems would have negative findings at relaparotomy.

Conclusions: None of the widely-used scoring systems to predict overall outcome in critically ill patients are of clinical value for the identification of patients with ongoing infection needing relaparotomy. There is a need to develop more specific tools to assist physicians in their daily monitoring and selection of these patients after the initial emergency laparotomy.
\end{abstract}

Trial registration number: ISRCTN: ISRCTN 51729393

\section{Background}

Our group conducted a trial among patients with abdominal sepsis comparing on-demand versus planned relaparotomy after the initial emergency operation (RELAP trial) [1]. We concluded that the on-demand strategy should be preferred, based on comparable clinical outcomes (12-month mortality $29 \%$ vs. $36 \%$; P = 0.22 ), but a substantial reduction of healthcare utilization and costs [1]. Planned relaparotomy yielded negative findings in $66 \%$ of patients and, thus, had no therapeutic effect in these patients. Improvement of

\footnotetext{
* Correspondence: j.j.kiewiet@amc.uva.nl

'Department of Surgery, Academic Medical Center, Amsterdam, The Netherlands

Full list of author information is available at the end of the article
}

patient selection for relaparotomy in the on-demand strategy however is necessary as $31 \%$ of these patients also had a negative relaparotomy [1].

The on-demand strategy implies a vigilant observation of the postoperative peritonitis patient. Improvement of outcome may follow improved monitoring following the initial emergency (index) laparotomy and adequate selection of patients with ongoing infection for reintervention. Presently, the on-demand strategy includes reoperation when patients show clinical deterioration or do not improve [1]. However, these conditions are not well defined. There is no consensus or guideline on patient monitoring to assist treating physicians in the selection of patients for reoperation.

\section{C) Biomed Central}

(C) 2011 van Ruler et al; licensee BioMed Central Ltd. This is an Open Access article distributed under the terms of the Creative Commons Attribution License (http://creativecommons.org/licenses/by/2.0), which permits unrestricted use, distribution, and reproduction in any medium, provided the original work is properly cited. 
Several commonly used scoring systems exist assessing the severity of disease in critically ill patients by predicting mortality. As these prognostic scores are widely incorporated in the daily treatment of ICU patients, we questioned whether they would be useful in selecting patients with ongoing abdominal infection needing a relaparotomy or reintervention (by relaparotomy or by percutaneous drainage).

\section{Methods}

\section{Study population}

The RELAP trial was a randomized controlled trial comparing relaparotomy on-demand with planned relaparotomy in patients with severe abdominal sepsis (APACHE-II > 10) receiving an emergency laparotomy. Details on inclusion criteria were reported in the article presenting the main results [1]. The 'on-demand' strategy was defined as performing a relaparotomy only in case of clinical deterioration or lack of improvement, monitored by physiological, laboratory and radiological parameters. The planned strategy was defined as performing a relaparotomy every 36 to 48 hours until the abdomen was macroscopically clean at the beginning of the final relaparotomy [1].

The trial cohort consisted of 229 patients of which 114 were randomly allocated to the on-demand strategy and 115 to the planned strategy. For the present study we included patients from both arms, but excluded those patients in whom the first relaparotomy took place more than 7 days after the initial emergency operation $(n=8)$. We maintained this 7-day period as ongoing infection directly associated with the primary disease, is presumed to occur within this time window. Moreover, the essential difference between the planned and on-demand strategy lies in the first relaparotomy being performed within two or three days after index surgery in the planned strategy. Commitment for relaparotomy on the second or third day is not part of the on-demand strategy, but reconciliation of the need for relaparotomy is made day by day in particular this first week.

\section{Outcomes}

Ongoing infection needing relaparotomy In the planned strategy group 'ongoing infection needing a relaparotomy' was defined as positive macroscopic findings at relaparotomy. Moreover, all planned patients who died within 14 days were classified as 'ongoing infection'. Death within this period was all cause. Within this short time frame from emergency laparotomy mortality was classified as due to (deterioration from) underlying abdominal sepsis. A negative relaparotomy (no residual infection or new pathology) was classified as 'no ongoing infection, not needing relaparotomy'.

In the on-demand treated patients only $48 \%$ received a first relaparotomy. These patients were classified as 'ongoing infection, needing a relaparotomy' in case of positive macroscopic findings at relaparotomy. In the $52 \%$ of on-demand patients not receiving relaparotomy obviously no direct visual abdominal inspection was performed. Therefore, we used a 14-day follow-up period as additional verification: a patient without visual verification that died within this period was classified as 'ongoing infection needing relaparotomy'. Patients without visual verification who survived at least 2 weeks after index surgery were classified as 'no ongoing infection, not needing relaparotomy' - assuming that if these patients would have received an early relaparotomy, findings would have been negative (Figure 1).

\section{Ongoing infection needing reintervention}

Patients needing reintervention $(n=82)$ included all patients that were classified as 'ongoing infection needing relaparotomy' supplemented by patients that received US- or CT-guided percutaneous drainage (PCD) of abdominal fluid with placement of drains for continuous drainage and lavage $(\mathrm{n}=11$; Figure 1$)$.

\section{Scoring systems}

Widely-used scoring systems were evaluated for predicting the need of relaparotomy after index operation. Scoring systems evaluated were the Acute Physiology and Chronic Health Evaluation (APACHE)-II score [2], the simplified Acute Physiology Score (SAPS)-II [3], the Mannheim Peritonitis Index (MPI) [4,5], the Multiple Organ Dysfunction Score (MODS) [6], the Sepsis-related Organ Failure Assessment (SOFA) score [7], and the APS, the physiological part extracted from the APACHE-II score [2].

The APACHE-II score was assessed, following the RELAP trial protocol, using the worst values of each independent constituent in a 24-hour time frame including the index laparotomy [1]. The SAPS-II and MPI were compiled by adding worst values of independent constituents in the initial 24 hours following index laparotomy.

Sequential scores, SOFA, APS and MODS were calculated on day 1 and 2, following index laparotomy by adding worst values of independent constituents measured that day (Table 1).

\section{Statistical analysis}

Baseline characteristics Demographic data, clinical characteristics and findings at index operation were compared between patients who did or did not have ongoing infection needing relaparotomy. Continuous variables were expressed as mean \pm standard deviation or median (25-75\% interquartile range) and compared, respectively, using Student's t-test or Mann-Whitney Utest depending on the skewness of the data. Categorical 


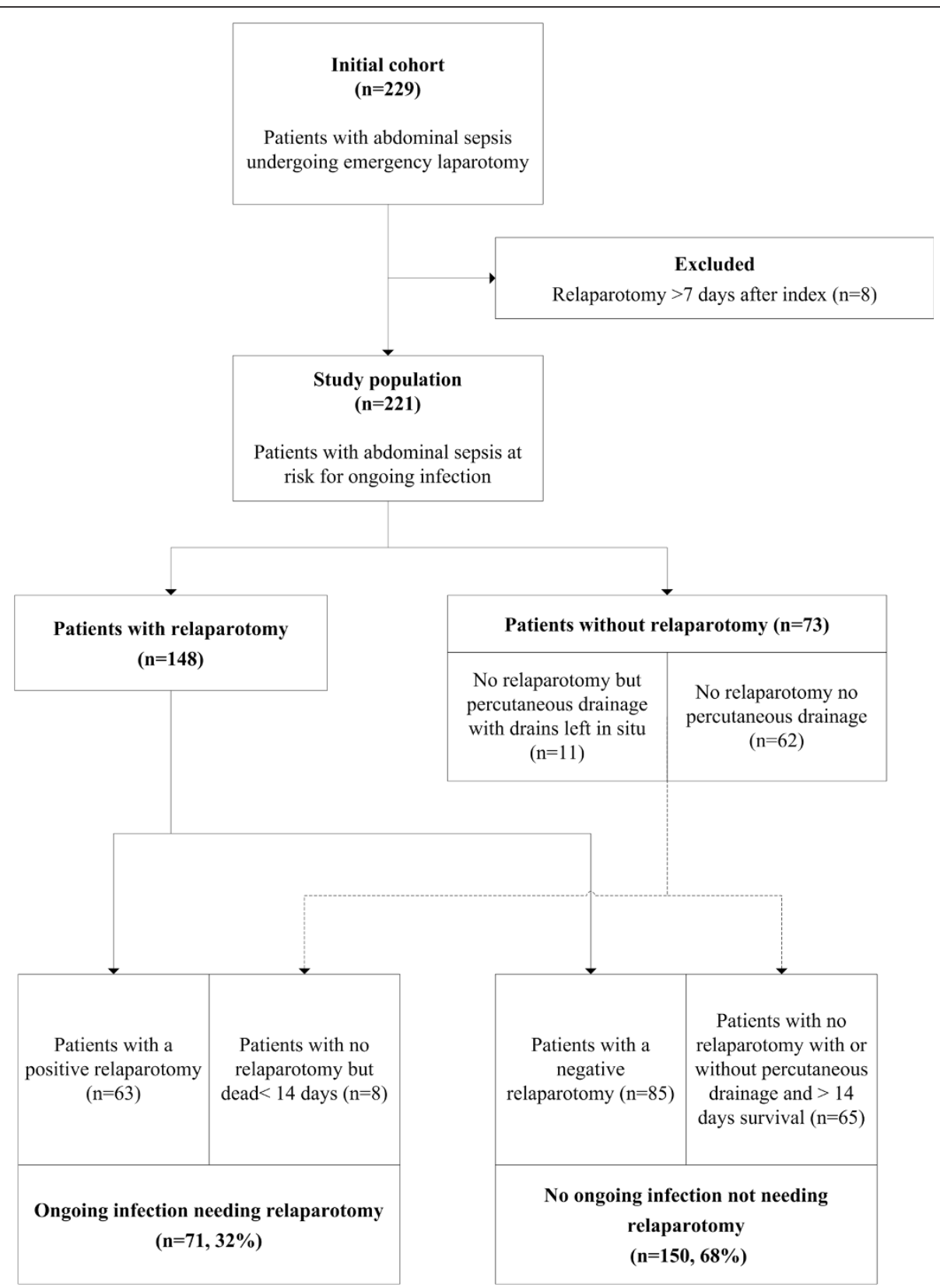

Figure 1 Flow chart showing patient selection and outcome definition.

variables were reported as absolute numbers (frequency with percentages) and analyzed using the $\chi^{2}$ test.

Predicting 'ongoing infection needing relaparotomy' To asses the ability of existing scoring systems to identify patients with ongoing infection needing relaparotomy we focused on the area under the receiver operating characteristic (ROC) curve (AUC). AUC's are presented for the APACHE-II, SAPS-II and MPI at index laparotomy. AUC's are presented for the MODS, SOFA score, and APS at day 1 , day 2 , and the absolute difference between day 2 and day 1 . Patients who were already dead and patients who already received a relaparotomy prior to the day of the measurements were not included in the analyses.

Logistic regression models were used to calculate these AUC's, also known as the concordance of c-statistics. These logistic regression models also provide odds ratios and 95\% confidence intervals (CI) expressing the strength of association between a risk score and the probability of ongoing infection needing relaparotomy.

Although we tried to harmonize the definition of ongoing infection needing relaparotomy across the two 
Table 1 Overview of components of the various existing scoring systems.

\begin{tabular}{|c|c|c|c|c|c|c|}
\hline & $\begin{array}{l}\text { APACHE- } \\
\text { II }\end{array}$ & $\begin{array}{l}\text { SAPS- } \\
\text { II }\end{array}$ & MPI & SOFA & MODS & APS \\
\hline Type of admission & & $\sqrt{ }$ & & & & \\
\hline Age & $\sqrt{ }$ & $\sqrt{ }$ & $\sqrt{ }$ & & & \\
\hline Gender & & & $\sqrt{ }$ & & & \\
\hline Chronic disease present & $\sqrt{ }$ & $\sqrt{ }$ & & & & \\
\hline Malignant comorbidity & & & $\sqrt{ }$ & & & \\
\hline Organ failure present & & & $\sqrt{ }$ & & & \\
\hline Temperature & $\sqrt{ }$ & $\sqrt{ }$ & & & & $\sqrt{ }$ \\
\hline White blood cell counts & & $\sqrt{ }$ & & & & $\sqrt{ }$ \\
\hline Oxygenation ${ }^{a}$ & $\sqrt{ }$ & $\sqrt{ }$ & & $\sqrt{ }$ & $\sqrt{ }$ & $\sqrt{ }$ \\
\hline Mechanical ventilation & & $\sqrt{ }$ & & & & \\
\hline Respiratory rate & $\sqrt{ }$ & & & & & $\sqrt{ }$ \\
\hline Arterial pH & $\sqrt{ }$ & & & & & $\sqrt{ }$ \\
\hline $\mathrm{HCO}^{-}$ & & $\sqrt{ }$ & & & & \\
\hline Cardiovascular state ${ }^{\mathrm{b}}$ & & & & $\sqrt{ }$ & & \\
\hline Heart rate & $\sqrt{ }$ & $\sqrt{ }$ & & & $\sqrt{ }$ & $\sqrt{ }$ \\
\hline Blood pressure ${ }^{c}$ & $\sqrt{ }$ & $\sqrt{ }$ & & $\sqrt{ }$ & $\sqrt{ }$ & $\sqrt{ }$ \\
\hline Hematocrit & $\sqrt{ }$ & & & & & $\sqrt{ }$ \\
\hline Creatinine & $\sqrt{ }$ & & & $\sqrt{ }$ & $\sqrt{ }$ & $\sqrt{ }$ \\
\hline Urine output & & $\sqrt{ }$ & & $\sqrt{ }$ & & \\
\hline Urea & & $\sqrt{ }$ & & & & \\
\hline Bilirubin & & $\sqrt{ }$ & & $\sqrt{ }$ & $\sqrt{ }$ & \\
\hline $\begin{array}{l}\text { Coagulation } \\
\text { (thrombocytes) }\end{array}$ & & & & $\sqrt{ }$ & $\sqrt{ }$ & \\
\hline Potassium & $\sqrt{ }$ & $\sqrt{ }$ & & & & $\sqrt{ }$ \\
\hline Sodium & $\sqrt{ }$ & $\sqrt{ }$ & & & & $\sqrt{ }$ \\
\hline Glasgow coma score & $\sqrt{ }$ & $\sqrt{ }$ & & $\sqrt{ }$ & $\sqrt{ }$ & \\
\hline $\begin{array}{l}\text { Disease specific } \\
\text { parameters }^{\mathrm{d}}\end{array}$ & & & $\sqrt{ }$ & & & \\
\hline \multicolumn{7}{|c|}{$\begin{array}{l}{ }^{a} \mathrm{PaO}_{2} \text { or } \mathrm{PaO}_{2} / \mathrm{FiO}_{2} \text { ratio } \\
\mathrm{b} \text { includes administration and dosage of (nor)epinephrine, dopamine or } \\
\text { dobutamine }\end{array}$} \\
\hline \multicolumn{7}{|c|}{$\begin{array}{l}\text { c systolic blood pressure, mean arterial pressure (MAP) or as part of the } \\
\text { pressure adjusted heart rate (PAR) }\end{array}$} \\
\hline${ }^{d}$ disease specific paramete & rs include du & Iration of & peritor & nitis, orig & gin, exten & \\
\hline
\end{tabular}

surgical strategies, we specifically examined whether there was a difference in predictive capability of one of the existing scoring system between patients treated by either surgical strategy. To examine this, logistic regression models were constructed containing type of surgical strategy, scoring system, and interaction between surgical strategy and scoring system. A significant Pvalue for the interaction term would indicate that the predictive ability of such a scoring system was different between surgical strategies, and probably related to a difference in defining the outcome.

If a scoring system had a significantly better discriminatory ability than can be expected by chance only (AUC > 0.6), we calculated a specific cut-off point that would have led to a sensitivity of $90 \%$. Applying that cut-off value would have identified $90 \%$ of all patients needing relaparotomy and consequently miss $10 \%$ of these patients. Such a cut-off analysis shows the consequences of applying a specific cut-off value and in particular it reveals the number of patients not needing a relaparotomy who would have been operated based upon a score above the cut-off value (1-specificity).

\section{Predicting 'ongoing infection needing reintervention'}

To assess the ability of existing scoring systems to identify patients with ongoing infection using the wider definition of 'needing reintervention', we determined the AUC's as measure of predictive value for 'ongoing infection needing reintervention' [8].

\section{Predicting mortality}

To verify consistency of data we examined the ability of examined scoring systems to predict mortality, the very purpose for which they were originally developed and validated. We again used AUC's to express the ability of each score to discriminate between patients who died in-hospital and those who survived their hospital admission [8].

\section{Missing values}

The various existing scoring systems were based on a multitude of different variables that had to be recorded prospectively per protocol on consecutive days upon inclusion of the RELAP trial. There were inevitably missing values in our dataset. Data checks were performed to detect any available missing values.

Although we had a low rate of missing values, in a compository score it would introduce uncertainty even when values of other variables were present. Therefore, we used multiple imputation to replace missing values with a set of plausible values that represent the uncertainty around the right value to impute. The multivariate relationships between all underlying variables were used to impute missing values (Markov Chain Monte Carlo, SAS). Appropriate transformations were applied to individual variables to improve normality $[9,10]$. For patients not admitted to the ICU at day 1 and/or day 2 normal values were imputed for components specifically associated with ICU care (central venous pressure, air oxygen pressure $\left(\mathrm{FiO}_{2}\right)$ in case of no oxygen suppletion, arterial oxygenation $\left(\mathrm{PaO}_{2}\right)$, and Glascow coma scale) [11].

The multiple imputed data sets were analyzed (one by one) using standard procedures (e.g. logistic regression) for complete data. Then the results from these analyses were combined to produce estimates and confidence intervals that properly reflect the uncertainty due to missing values. We used a total of ten rounds of 
imputation to estimate the final parameters with their confidence intervals $[9,10,12-14]$.

P-values less than 0.05 were considered statistically significant. Statistical analyses were carried out using SAS 9.1 (SAS Institute, Cary, NC, USA).

\section{Results}

\section{Patient inclusion}

The study population consisted of 221 patients at risk for ongoing infection after emergency laparotomy because of secondary peritonitis. Figure 1 shows that using the specified outcome definition 71 patients (32\%) were classified as 'ongoing infection needing relaparotomy'.

For the sequential scoring systems, 3 patients were excluded from the analyses at day 1 , because 1 patient had a relaparotomy within several hours of the index laparotomy and 2 patients had died. For analyses at day 2 some more patients were excluded from analyses: 12 patients had already undergone a relaparotomy and 1 patient had died, leaving 205 patients available for analyses (needing relaparotomy $\mathrm{n}=64$ ).

Table 2 lists the demographic and baseline characteristics of both outcome groups. More than $90 \%$ of patients had been admitted to the ICU. As can be expected, patients classified as 'ongoing infection needing relaparotomy' had a significant longer ICU stay and high mortality rate.

\section{Predicting 'ongoing infection needing relaparotomy'}

None of the interactions between existing scoring systems and the applied surgical strategy (on-demand or planned relaparotomy strategy) were significant with Pvalues ranging from 0.098 to 0.982 . Therefore, all ROC analyses were based on the total cohort of patients from the RELAP trial (Table 3). The ROC curves showing pairs of sensitivity and specificity for possible cut-off values are presented in Figure 2.

The single time point severity of disease scores, APACHE-II score, SAPS-II and MPI showed no predictive value for 'ongoing infection needing relaparotomy' with AUC's all below 0.6 (Table 3, Figure 2).

The SOFA score had no predictive value on day 1 (AUC 0.57, 95\%CI 0.49-0.65) but improved to modest on day 2 (AUC 0.60, 95\%CI 0.52-0.69; Table 3, Figure 2 ). The absolute difference (delta SOFA measurements between day 2 and day 1) showed no discriminatory value. The MODS also showed no discriminatory value for ongoing infection on either consecutive day (Table 3 , Figure 2).

The APS, however, showed a modest discriminatory ability at day 1 with an AUC of 0.61 (95\%CI 0.52-0.69), at day 2 the AUC was 0.56 (95\%CI $0.47-0.65$; Table 3, Figure 2).

\section{$90 \%$ sensitivity}

For scoring systems that performed significantly better than chance, we determined a cut-off score that would produce a sensitivity of $90 \%$ and then calculated the proportion of patients undergoing an unnecessary relaparotomy (1-specificity).

A score of 3.1 determined for the APS would have identified $90 \%$ of the patients requiring a relaparotomy, but the corresponding specificity was only $17 \%$. Based on this cut-off value, the positive predictive value would have been $33 \%$, indicating that for all 186 patients with a score above this cut-off of 3.1 only 62 patients would have been rightfully reoperated, and 124 patients would have been reoperated under suspicion of ongoing abdominal infection but with negative findings at relaparotomy. The negative predictive value, based on this cut-off value, would have been $78 \%$, indicating that 25 of the 32 patients with a score under the cut-off value of 3.1 would rightfully not have been reoperated. However, 7 patients with ongoing infection needing relaparotomy would have been withheld from relaparotomy (Table 4).

The $90 \%$ sensitivity cut-off for day 2 SOFA scores (1.4) would have a positive predictive value of $32 \%$ and a negative predictive value of $73 \%$ (Table 4).

Table 2 Demographic, initial peritonitis and recovery data for all 221 included patients.

\begin{tabular}{|c|c|c|c|c|c|}
\hline \multirow{2}{*}{$\begin{array}{l}\text { Characteristic } \\
\text { Median age (IQR) }\end{array}$} & \multicolumn{2}{|c|}{$\begin{array}{l}\text { Ongoing infection needing relaparotomy } \\
\qquad(\mathrm{n}=71)\end{array}$} & \multicolumn{2}{|c|}{$\begin{array}{l}\text { No ongoing infection, not needing relaparotomy } \\
\qquad(n=150)\end{array}$} & \multirow{2}{*}{$\begin{array}{r}\text { P-value } \\
0.36\end{array}$} \\
\hline & 69 & (57 to 74$)$ & 70 & (57 to 76$)$ & \\
\hline Male n (\%) & 38 & $(54 \%)$ & 65 & $(43 \%)$ & 0.16 \\
\hline Postoperative peritonitis n (\%) & 32 & $(45 \%)$ & 71 & $(47 \%)$ & 0.75 \\
\hline Generalized peritonitis n (\%) & 47 & $(66 \%)$ & 88 & $(59 \%)$ & 0.48 \\
\hline ICU admission n (\%) & 69 & $(97 \%)$ & 135 & $(90 \%)$ & 0.061 \\
\hline Length of ICU stay & 12 & (7 to 32$)$ & 7 & (4 to 16$)$ & 0.001 \\
\hline Length of index hospital stay & 32 & (17 to 74$)$ & 28 & (17 to 49$)$ & 0.28 \\
\hline In-hospital mortality n (\%) & 26 & $(37 \%)$ & 23 & $(15 \%)$ & $<0.001$ \\
\hline
\end{tabular}


Table 3 Mean scores with associated standard deviations (SD) compared for patients with 'ongoing infection needing relaparotomy' ( $n=71)$ and patients with 'no ongoing infection, not needing relaparotomy' $(n=150)$.

\begin{tabular}{|c|c|c|c|c|}
\hline Score & Ongoing infection [Mean score (SD)] & No ongoing infection, [Mean score (SD)] & AUC $(95 \% \mathrm{Cl})$ & P-value ${ }^{a}$ \\
\hline APACHE-II & $16.1(4.8)$ & $15.8(4.0)$ & 0.50 (0.42 to 0.58$)$ & 0.961 \\
\hline SAPS-II & $40.2(12.3)$ & $36.0(11.3)$ & 0.59 (0.51 to 0.67$)$ & 0.033 \\
\hline MPI & $26.8(6.9)$ & $26.5(7.9)$ & 0.51 (0.43 to 0.59$)$ & 0.824 \\
\hline SOFA (day 1$)^{\mathrm{b}}$ & $7.3(3.8)$ & $6.4(3.4)$ & 0.57 (0.49 to 0.65$)$ & 0.108 \\
\hline SOFA (day 2) ${ }^{c}$ & $6.8(3.8)$ & $5.8(3.4)$ & 0.60 (0.52 to 0.69$)$ & 0.017 \\
\hline SOFA Delta (day 2-1) ${ }^{c}$ & $-0.17(2.2)$ & $-0.93(2.3)$ & $0.58(0.50$ to 0.66$)$ & 0.073 \\
\hline MODS (day 1$)^{b}$ & $5.0(3.0)$ & $4.3(2.7)$ & 0.56 (0.48 to 0.64$)$ & 0.141 \\
\hline MODS (day 2) ${ }^{c}$ & $4.2(3.0)$ & $3.7(2.6)$ & 0.54 (0.45 to 0.63$)$ & 0.349 \\
\hline MODS Delta (day 2-1) & $-0.48(1.8)$ & $-0.60(1.8)$ & $0.52(0.43$ to 0.60$)$ & 0.726 \\
\hline APS (day 1$)^{b}$ & $8.3(4.6)$ & $6.6(3.6)$ & 0.61 (0.52 to 0.69$)$ & 0.012 \\
\hline APS (day 2) ${ }^{c}$ & $6.8(3.7)$ & $5.9(3.2)$ & 0.56 (0.47 to 0.65$)$ & 0.154 \\
\hline APS Delta (day 2-1) & $-1.03(3.7)$ & $-0.64(3.7)$ & 0.55 (0.46 to 0.63$)$ & 0.277 \\
\hline
\end{tabular}

${ }^{a}$ P-value wether different from an AUC of 0.50

${ }^{b}$ patients deceased on day $0(n=2)$ and patient receiving relaparotomy on day $0(n=1)$ excluded

${ }^{c}$ patients deceased on day 0 and $1(n=3)$ and patients receiving relaparotomy on day 0 and $1(n=13)$ excluded

\section{Predicting ongoing infection needing reintervention}

Eighty-two patients were classified as 'ongoing infection needing reintervention' (Figure 1). Only the APS at day 1 showed an AUC 0.6 for prediction of 'ongoing infection needing reintervention’ (95\%CI 0.52-0.68; Table 5).

\section{Predicting mortality}

All evaluated scoring systems were predictive of mortality in peritonitis patients, as score AUC's were significantly different from an AUC of 0.5 (Table 5).

\section{Discussion}

The predictive value of available scoring systems, in particular those that can be assessed sequentially, for ongoing abdominal infection needing relaparotomy is not known. In clinical practice changes in organ functions are seen as useful triggers to expand diagnostic tools or intervention. However, only the SOFA score and APS had equally modest discriminatory ability for predicting ongoing infection needing relaparotomy. Furthermore, they showed an extremely low specificity for a $90 \%$ sensitivity. Broadening the definition of ongoing abdominal infection by patients needing reintervention (relaparotomy or percutaneous drainage) did not enhance identification of patients with persistent peritonitis.

The RELAP trial concludes that the on-demand strategy is preferred [1]. Stringent monitoring of patients is a vital component of this strategy. A scoring system can aid in adequate and timely identification of patients for relaparotomy. Ideally, such a prediction model should be a sequential score. Changes in organ failure may be of better value in objectifying the clinical course of the disease, in particular since postoperative (follow-up)

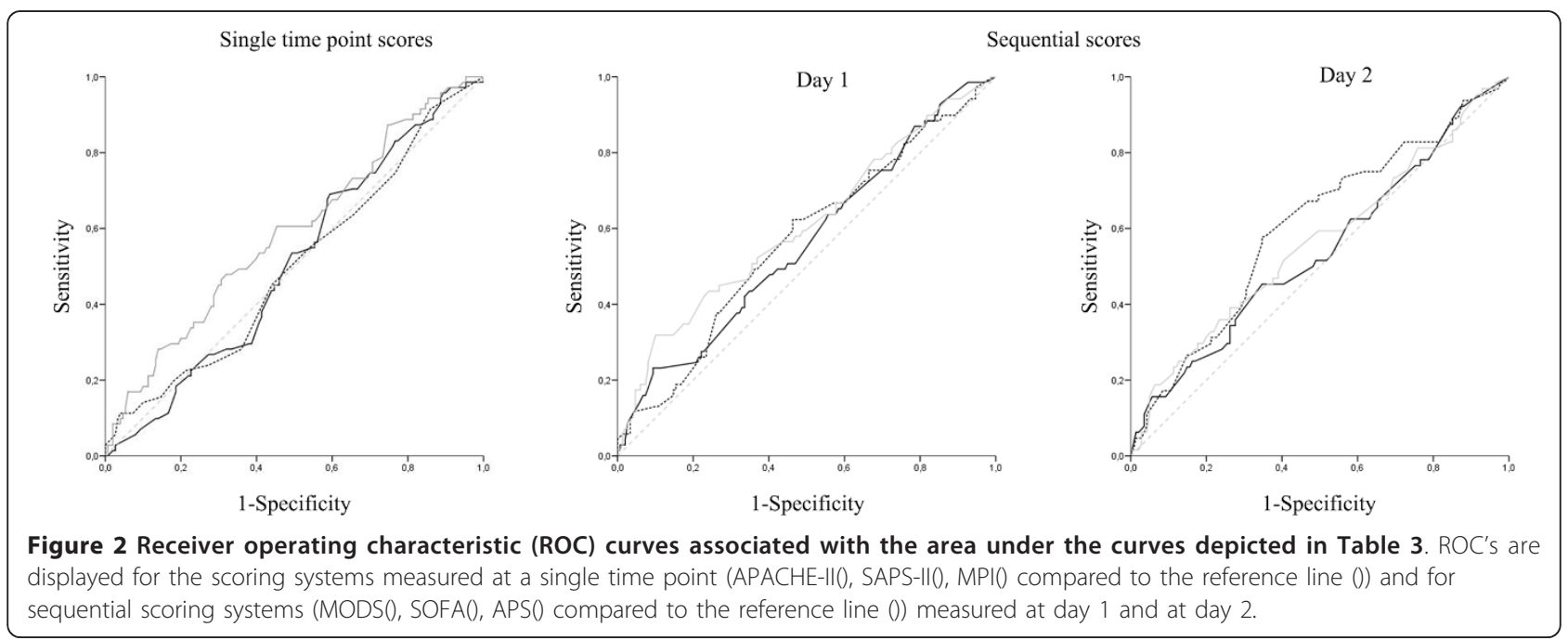


Table 4 Performance of scoring systems, moderately predictive for 'ongoing infection needing relaparotomy' (AUC > 6.0; SOFA day 2 and APS day 1), in selecting patients for relaparotomy using a cut-off value based on a $90 \%$ sensitivity.

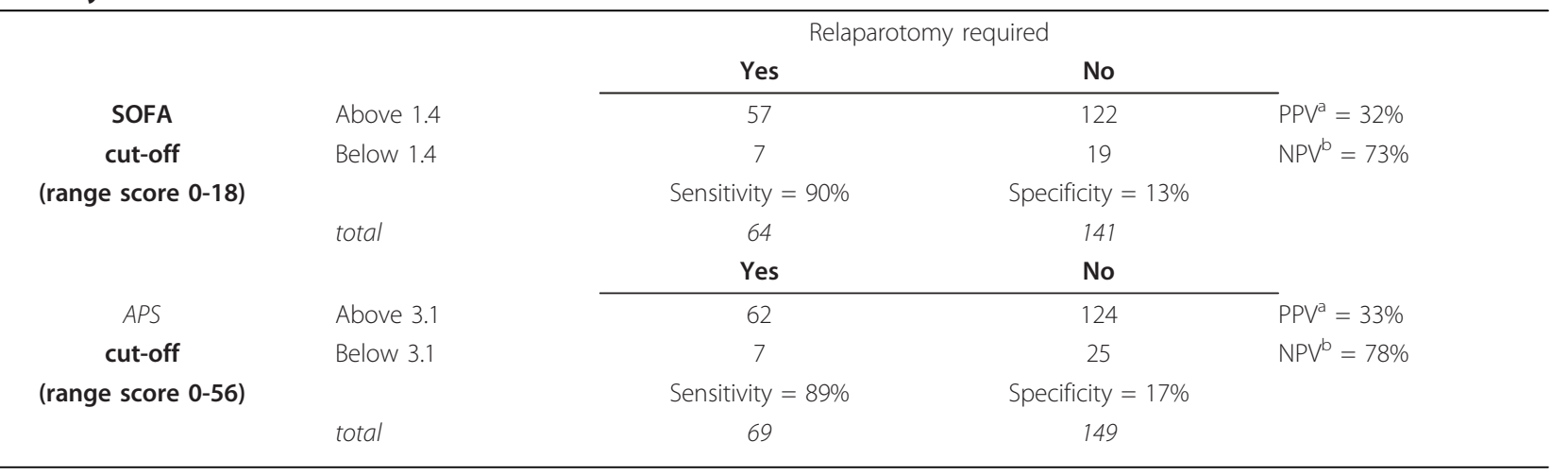

${ }^{a}$ positive predictive value

${ }^{b}$ negative predictive value

variables are more predictive than variables that become available during index laparotomy [15].

We were surprised by the low performance of these well-known scoring systems, as most of these scores quantify organ function. However, none of the evaluated scoring systems were originally developed to predict the need of a relaparotomy for ongoing peritonitis following emergency laparotomy in the acute phase of the disease [2-7]. All scores, except the MPI, have been developed to predict death for ICU patients in general and for groups of patients (strata) rather than predicting death for individual patients $[2,3,6,7]$. Although the MPI is specifically developed for patients with abdominal sepsis, it is focused on prediction of death rather than occurrence of ongoing infection [16]. Also, the MPI largely consists of peritonitis-related data, determined at the initial emergency laparotomy [5]. These variables are described to be less predictive than physiological postoperative variables [15]. All scores, indeed, did better at predicting death, as they are developed and validated to do.

Prognostic relevance of the SOFA score in combination with inflammatory parameters was also found in a recent study conducted by Zügel et al., even though

Table 5 Predictive value comparing patients needing a reintervention $(n=82)$ with not needing reintervention and for inhospital mortality $(n=49)$.

\begin{tabular}{|c|c|c|c|}
\hline & Score & AUC $(95 \% \mathrm{Cl})$ & P-value whether AUC different from 0.5 \\
\hline \multicolumn{4}{|l|}{ Reintervention $(n=82)$} \\
\hline & APACHE-II & 0.49 (0.41 to 0.57$)$ & 0.860 \\
\hline & SAPS-II & 0.56 (0.48 to 0.64$)$ & 0.145 \\
\hline & MPI & 0.52 (0.44 to 0.60$)$ & 0.666 \\
\hline & SOFA (day 1) ${ }^{a}$ & 0.55 (0.47 to 0.63$)$ & 0.205 \\
\hline & SOFA (day 2) ${ }^{b}$ & 0.57 (0.49 to 0.65$)$ & 0.088 \\
\hline & MODS (day 1) ${ }^{a}$ & $0.55(0.47$ to 0.63$)$ & 0.199 \\
\hline & MODS (day 2) ${ }^{b}$ & 0.53 (0.45 to 0.61$)$ & 0.469 \\
\hline & APS (day 1)a & $0.60(0.52$ to 0.68$)$ & 0.019 \\
\hline & APS (day 2) ${ }^{b}$ & $0.53(0.44$ to 0.61$)$ & 0.531 \\
\hline \multicolumn{4}{|l|}{ Inhospital mortality $(n=49)$} \\
\hline & APACHE-II & 0.74 (0.65 to 0.82$)$ & $<0.001$ \\
\hline & SAPS-II & 0.80 (0.73 to 0.87$)$ & $<0.001$ \\
\hline & MPI score & 0.60 (0.52 to 0.69$)$ & 0.026 \\
\hline & SOFA (day 1) ${ }^{c}$ & $0.72(0.63$ to 0.81$)$ & $<0.001$ \\
\hline & MODS (day 1) ${ }^{c}$ & 0.76 (0.68 to 0.83$)$ & $<0.001$ \\
\hline & APS (day 1) ${ }^{c}$ & $0.68(0.59$ to 0.77$)$ & $<0.001$ \\
\hline
\end{tabular}

\footnotetext{
${ }^{a}$ patients deceased on day $0(n=2)$ and patient receiving relaparotomy on day $0(n=1)$ excluded

${ }^{b}$ patients deceased on day 0 and $1(n=3)$ and patients receiving relaparotomy on day 0 and $1(n=13)$ excluded

c patients deceased on day $0(n=2)$ and patient receiving relaparotomy on day $0(n=1)$ excluded
} 
results were based on only a small number of events [17]. Torer et al. and Tan et al. identified possible prognostic relevance for the MPI in retrospective cohorts with patients with secondary peritonitis due to postoperative complications and community acquired perforations of small bowel and colon [17-20]. However, quantification of or changes in organ failure does not seem to differentiate between ongoing organ failure due to abdominal sepsis despite source control of the initial causative focus and ongoing abdominal infection.

For the non-reoperated patients, the time frame in which the predictor status of the sequential scoring systems was assessed was less precise. Our best deduction was to evaluate the scores during the clinical phase in which the dilemma of early relaparotomy is most prominent; day 1 and day 2 after the initial emergency laparotomy, for all included patients. In view of the disappointing predictive values, it is unlikely that extension of assessment after day 2 would have revealed completely different results.

Patients included in this study were randomized to the on-demand or the planned strategy [1]. This enhances the generalizability of the results but foremost eliminates selection bias in choice of practiced treatment strategies. Differences in these treatment arms did lead to differential verification, but not necessarily to verification bias. Another option would have been to use only the planned arm of the trial, as all these patients were reoperated and had uniform outcome verification. Instead, all existing scoring systems were tested for the assumption that both the on-demand and planned strategy could be combined for the above analyses and we found no significant interaction between treatment strategies and predictive ability of the various scoring systems. This means that the predictive ability of existing scoring systems is comparable for both on-demand and planned treated patients. Importantly, also the proportion of events (positive findings at relaparotomy) was comparable for both strategies ( $29 \%$ for on-demand vs. $32 \%$ for planned) [1].

For clinical purposes, discriminatory power is more important than stratification. A $90 \%$ level of sensitivity was employed, as it is considered worse to mistakenly not re-operate a patient with ongoing infection needing relaparotomy than it is to reoperate a patient on the suspicion of ongoing infection but with negative findings $[15,21]$. The approximate of $90 \%$ sensitivity was chosen to determine a cut-off for adequate scoring systems, reflecting the trade-off between a false positive prediction of peritonitis (negative relaparotomy) and a false negative prediction of peritonitis (no relaparotomy although one is needed). Nevertheless, performing too many negative relaparotomies should be avoided [22]. None of the scoring systems had a clinical important predictive value nor demonstrated a clinically useful discriminatory ability. In order not to withhold relaparotomy from too many patients who need treatment for ongoing infection, an unacceptable high proportion of inappropriate relaparotomies would be performed based on the scores.

All presented, existing scoring systems lack the additional information derived from diagnostic imaging techniques which is likely valuable for selection of patients with ongoing infection needing reintervention. For patients suspected of abdominal infection following elective abdominal surgery, CT imaging has a high diagnostic accuracy [23]. The exact value of diagnostic imaging in operated peritonitis patients with suspected ongoing abdominal infection is not known, as consequences from management decisions based on $\mathrm{CT}$ results have not been evaluated yet. Future research is needed to determine the exact accuracy of CT scanning in on-demand treated peritonitis patients who are suspected of ongoing infection.

\section{Conclusions}

None of the existing and widely used severity-of-disease scores, specifically developed for critically ill patients, was clinically useful in the identification of patients with ongoing infection needing a relaparotomy. Therefore, new tools need to be developed that specifically incorporate parameters indicative for ongoing abdominal infection, rather than merely ongoing organ failure, in patients with abdominal sepsis. Preferentially, these specific tools combine clinical findings, laboratory measurements and results from diagnostic imaging tests to assist the multidisciplinary team in selecting patients for reintervention to treat ongoing abdominal infection.

\section{Acknowledgements}

Financial Support

Dutch Organization for Health Research and Development (ZonMw), The

Hague, The Netherlands. Health Care Efficiency Program. Grant number: 94502-028. The funding body did not have a role in the study design,

collection/analysis/interpretation of data, the writing of the manuscript or

the decision to submit this manuscript for publication.

Paper presentation

This paper has been presented at a meeting of the Surgical Infection Society North America and Europe (SIS-NA/E) in Chicago, Illinois, USA, May 2009.

Dutch Peritonitis Study Group

RELAP trial clinical centers and investigators of the Dutch Peritonitis Study Group All investigators are from Departments of Surgery unless specified (E) Clinical Epidemiology and Biostatistics (E), (I) Intensive Care or Medical Psychology (MP).

O van Ruler MD; KR Boer PhD (E); JB Reitsma MD, PhD (E); CW Mahler MD; EA Reuland MD; JWO van Till MD, PhD; BC Opmeer PhD (E); PMM Bossuyt PhD (E); MJ Schultz MD, PhD (I); MA Sprangers MD, PhD (MP); DJ Gouma MD, PhD; H Obertop MD, PhD; CAJM de Borgie MD, PhD (E); MA

Boermeester MD, PhD, Academic Medical Center, Amsterdam; EPh Steller MD, PhD; P. Tanis MD, PhD; H Hart MD (I), St Lucas Andreas Hospital, Amsterdam; MF Gerhards MD, PhD; M Guijt MD; HM Oudemans MD, PhD (I), Onze Lieve Vrouwe Gasthuis, Amsterdam; K. Bosscha MD, PhD; E Ritchie MD; M Vermeer, Bosch Medical Centre, Den Bosch; PW de Graaf MD, PhD; B van 
Etten MD, PhD; C Haazer (I); E Salm MD, PhD (I); Reinier de Graaf Hospital, Delft; B Lamme MD, PhD; EJ Hesselink MD, PhD; H Rommes MD, PhD (I), Gelre Hospitals, Lucas Hospital Apeldoorn; RJ Oostenbroek MD, PhD; L te Velde MD; G Govaert MD; HH Ponssen MD (I), Albert Schweitzer Hospital, Dordrecht; HG Gooszen MD, PhD; MK Dinkelman MD; LPH Leenen MD, PhD (I), University Medical Centre Utrecht; EGJM Pierik MD, PhD; KWW Lansink MD; J Bakker MD, PhD (I), Isala Clinics, Zwolle.

\section{Author details}

'Department of Surgery, Academic Medical Center, Amsterdam, The Netherlands. ${ }^{2}$ Department of Clinical Epidemiology, Biostatistics and Bioinformatics, Academic Medical Center, Amsterdam, the Netherlands.

\section{Authors' contributions}

All authors have read and approved the final manuscript. OR designed the study, collected, analyzed and interpreted data. Furthermore she wrote the manuscript. JK analyzed and interpreted data, and drafted the manuscript. $\mathrm{KB}$ analyzed and interpreted data, and drafted the manuscript. BL helped to collect data and drafted the manuscript. DG designed the study and drafted the manuscript. MB designed the study, interpreted data, and drafted the manuscript. JR analyzed and interpreted data, and drafted the manuscript.

\section{Competing interests}

The authors declare that they have no competing interests.

Received: 16 May 2011 Accepted: 23 December 2011

Published: 23 December 2011

\section{References}

1. van Ruler $\mathrm{O}$, Mahler CW, Boer KR, Reuland EA, Gooszen HG, Opmeer BC, de Graaf PW, Lamme B, Gerhards MF, Steller EP, van Till JW, de Borgie CJ, Gouma DJ, Reitsma JB, Boermeester MA, Dutch Peritonitis Study Group: Comparison of on-demand versus planned relaparotomy strategy in patients with severe peritonitis. A randomized trial. JAMA 2007, 298:865-873.

2. Knaus WA, Draper EA, Wagner DP, Zimmerman JE: APACHE II: a severity of disease classification system. Crit Care Med 1985, 13:818-829.

3. Le Gall Jr, Lemeshow S, Saulnier F: A new Simplified Acute Physiology Score (SAPS II) based on a European/North American multicenter study. JAMA 1993, 270:2957-2963.

4. Linder MM, Wacha H, Feldmann U, Wesch G, Streifensand RA, Gundlach E: The Mannheim peritonitis index. An instrument for the intraoperative prognosis of peritonitis. Chirurg 1987, 58:84-92.

5. Wacha H, Linder MM, Feldmann U, Wesch G, Gundlach E, Steifensand RA: Mannheim Peritonitis Index - prediction of risk of death from peritonitis: construction of a statistical and validation of an emperically based index. Theor Surg 1987, 169-177.

6. Marshall JC, Cook DJ, Christou NV, Bernard GR, Sprung CL, Sibbald WJ: Multiple organ dysfunction score: a reliable descriptor of a complex clinical outcome. Crit Care Med 1995, 23:1638-1652.

7. Vincent $\mathrm{J}$, Moreno R, Takala J, Willatts $\mathrm{S}$, De Mendonça A, Bruining $\mathrm{H}$, Reinhart CK, Suter PM, Thijs LG: The SOFA (Sepsis-related Organ Failure Assessment) score to describe organ dysfunction/failure. On behalf of the Working Group on Sepsis-Related Problems of the European Society of Intensive Care Medicine. Intensive Care Med 1996, 22:707-710.

8. Hanley JA, McNeil BJ: The meaning and use of the area under a receiver operating characteristic (ROC) curve. Radiology 1982, 143:29-36.

9. Schafer JL: Multiple imputation: a primer. Stat Methods Med Res 1999, 8:3-15.

10. Rubin DB: Multiple imputation after 18+ years. Journal of the American Statistical Association 1996, 91:473-489.

11. Timsit JF, Fosse JP, Troche G, De Lassence A, Alberti C, Garrouste-Orgeas M, Bornstain C, Adrie C, Cheval C, Chevret S: Calibration and discrimination by daily Logistic Organ Dysfunction scoring comparatively with daily Sequential Organ Failure Assessment scoring for predicting hospital mortality in critically ill patients. Crit Care Med 2002, 30:2003-2013.

12. Donders AR, van der Heijden GJ, Stijnen T, Moons KG: Review: a gentle introduction to imputation of missing values. J Clin Epidemiol 2006, 59:1087-1091

13. Newgard CD, Haukoos JS: Advanced statistics: missing data in clinical research-part 2: multiple imputation. Acad Emerg Med 2007, 14:669-678.
14. Little RJA, Rubin DB: Statistical analysis with missing data. New York, NY: Wiley.

15. van Ruler O, Lamme B, Gouma DJ, Reitsma JB, Boermeester MA: Variables associated with positive findings at relaparotomy in patients with secondary peritonitis. Crit Care Med 2007, 35:468-476.

16. Wacha H, Hau T, Dittmer R, Ohmann C: Risk factors associated with intraabdominal infections: a prospective multicenter study. Peritonitis Study Group. Langenbecks Arch Surg 1999, 384:24-32.

17. Zügel NP, Kox M, Lichtwark-Aschoff M, Gippner-Steppert C, Jochum M: Predictive relevance of clinical scores and inflammatory parameters in secondary peritonitis. Bull Soc Sci Med Grand Duche Luxemb 2011, 1:41-71.

18. Torer N, Yorganci K, Elker D, Sayek I: Prognostic factors of the mortality of postoperative intraabdominal infections. Infection 2010, 38:255-260.

19. Tan KK, Bang SL, Sim R: Surgery for small bowel perforation in an Asian population: predictors of morbidity and mortality. J Gastrointest Surg 2010, 14:493-499.

20. Tan KK, Hong CC, Zhang J, Liu JZ, Sim R: Predictors of outcome following surgery in colonic perforation: an institution's experience over 6 years. $J$ Gastrointest Surg 2011, 15:277-284.

21. Schein M: Surgical management of intra-abdominal infection: is there any evidence? Langenbecks Arch Surg 2002, 387:1-7.

22. Zügel N, Siebeck M, Geissler B, Lichtwark-Aschoff M, Gippner-Steppert C, Witte J, Jochum M: Circulating mediators and organ function in patients undergoing planned relaparotomy vs conventional surgical therapy in severe secondary peritonitis. Arch Surg 2002, 137:590-599.

23. Go HL, Baarslag HJ, Vermeulen H, Lameris JS, Legemate DA: A comparative study to validate the use of ultrasonography and computed tomography in patients with post-operative intra-abdominal sepsis. Eur $J$ Radiol 2005, 54:383-387.

\section{Pre-publication history}

The pre-publication history for this paper can be accessed here: http://www.biomedcentral.com/1471-2482/11/38/prepub

doi:10.1186/1471-2482-11-38

Cite this article as: van Ruler et al:: Failure of available scoring systems to predict ongoing infection in patients with abdominal sepsis after their initial emergency laparotomy. BMC Surgery 2011 11:38.

\section{Submit your next manuscript to BioMed Central and take full advantage of:}

- Convenient online submission

- Thorough peer review

- No space constraints or color figure charges

- Immediate publication on acceptance

- Inclusion in PubMed, CAS, Scopus and Google Scholar

- Research which is freely available for redistribution

Submit your manuscript at www.biomedcentral.com/submit
C Biomed Central 